\title{
CORRIGENDUM
}

\section{Greenland meltwater as a significant and potentially bioavailable source of iron to the ocean}

Maya P. Bhatia, Elizabeth B. Kujawinski, Sarah B. Das, Crystaline F. Breier, Paul B. Henderson and Matthew A. Charette Nature Geoscience 6, 274-278 (2013); published online 10 March 2013; corrected after print 29 April 2013.

In the version of this Letter originally published, in the first sentence of the final paragraph, the 1992-2010 percentage increase in freshwater flux from the GrIS into the North Atlantic Ocean (as reported in ref. 25) was incorrectly stated to be $136 \%$. The correct figure is $38 \%$. This has been corrected in the PDF and HTML versions. 